\title{
Analysis of heritage stones and model wall paintings by pulsed laser excitation of \\ Raman, laser-induced fluorescence and laser-induced breakdown spectroscopy signals with a hybrid system
}

\author{
A. Martínez-Hernández ${ }^{1}$, M. Oujja ${ }^{1}$, M. Sanz ${ }^{1 *}$, E. Carrasco ${ }^{1,3}$, V. Detalle ${ }^{2}$, M. Castillejo ${ }^{1}$ \\ ${ }^{1}$ Instituto de Química Física Rocasolano (CSIC), Serrano 119, 28006 Madrid, Spain \\ ${ }^{2}$ Centre de Recherche et de Restauration des Musées de France, 14 quai F. Mitterrand 75001, \\ Paris, France \\ ${ }^{3}$ Present address: IMDEA Nanociencia, 28049 Madrid, Spain \\ *E-mail: mikel.sanz@iqfr.csic.es
}

\begin{abstract}
Analysis of heritage stone samples, alabaster, gypsum, limestone and marble, and model wall paintings was carried out with a laboratory, hybrid system based on the pulsed laser excitation of Raman, laser-induced fluorescence and laser-induced breakdown spectroscopy signals. The system is based on a nanosecond Q-switched Nd:YAG laser operating at its second (532 nm), third (355 nm) and fourth (266 nm) harmonics and a spectrograph coupled to a time-gated intensified charge coupled device for spectral analysis and detection with temporal resolution. For the stone samples, Raman spectra upon excitation at 355 and $532 \mathrm{~nm}$ display the characteristic vibration modes of $\mathrm{SO}_{4}{ }^{2-}$ of calcium sulphate, in alabaster and gypsum, and of free $\mathrm{CO}_{3}{ }^{2-}$ of calcium carbonate, in limestone and marble. Simultaneously acquired laserinduced fluorescence spectra reveal characteristic bands that help to distinguish materials of the same base chemical composition. Elemental composition of stone samples is obtained by laser-induced breakdown spectroscopy upon excitation at $355 \mathrm{~nm}$. Spectra of all stone samples reveal their elemental composition that includes $\mathrm{Ca}, \mathrm{Na}, \mathrm{Mn}$ and $\mathrm{Sr}$ and the presence of molecular species such as $\mathrm{CN}, \mathrm{C}_{2}$ and $\mathrm{CaO}$. Additional emission lines ascribed to $\mathrm{Mg}, \mathrm{Si}, \mathrm{Al}$ and $\mathrm{K}$, appear with different intensities according to the nature of the stone material. Model wall paintings, based on a red pigment, prepared as fresco or mixed with two different binders, were also studied. The complementary information provided by the three spectroscopic modes allows the identification of the pigment as red vermillion and of the different preparations based on the pigment alone or in mixtures with linseed oil and egg yolk binders.
\end{abstract}




\section{Introduction}

Laser spectroscopies, such as Raman, laser-induced fluorescence (LIF) and laser-induced breakdown spectroscopy (LIBS) are widely used for analysis of materials and substrates of cultural heritage [1-12]. Raman and LIBS have been commonly used together as they provide complementary information on molecular and elemental composition, respectively and in several studies, this combined approach has led to the integrated characterization of pigments and minerals [13-17]. Raman spectroscopy yields information on superficial molecular composition and has become an important technique in the investigation of archaeological and artistic substrates and objects $[8,9]$. Raman signals are usually collected upon excitation with a continuous wave laser but the use of pulsed laser excitation becomes possible by using intensified charge coupled device (ICCD) cameras synchronized with the laser pulse for signal acquisition. In this case, by applying a short temporal gate it is possible to discriminate the Raman bands from other contributions, including luminescence and background scattered light [18-20]. LIBS, in turn, involves the ablation of a minute quantity of material, ejected as a micro plasma from the surface sample, and requires the excitation with a focused pulsed laser [1-6]. LIBS has been used in a wide variety of analytical applications for the qualitative, semiquantitative and quantitative analysis of materials and offers specific features of particular relevance in the context of analysis of cultural heritage materials [1, 2, 10-12]. A recent work has showed the effect of irradiation wavelength on the analysis by LIBS of painting samples, concluding that short wavelengths favour the characterization of this kind of substrates [21].

The implementation of a hybrid concept combining Raman and LIBS techniques allows interrogating samples using pulsed laser beams with identical characteristics. In the last years, several instruments with Raman and LIBS capabilities based on a pulsed source, generally using different harmonics from a Q-switched Nd:YAG laser (fundamental emission at $1064 \mathrm{~nm}$ ), have been developed [22-32]. These systems have been used in the context of cultural heritage [2225], standoff analysis of explosive materials [26], analysis of geological samples [27], etc., and some prototypes have been reported in relation to planetary missions [28-32]. Ref. [33] provides a review of basic instrumental principles, design requirements and technological aspects of the combination of Raman and LIBS.

The combined use of Raman spectroscopy and LIBS serves the purpose of identifying the constituent materials in inorganic samples. However when dealing with organic substrates, the frequent presence of fluorescent emissions can mask the Raman signals [22]. In these cases, LIF spectroscopy provides complementary analytical information $[3,7,34-37]$ and, due to its high sensitivity, facilitates the detection of trace species. Integrating LIF capabilities with Raman and LIBS has shown to be particularly advantageous for the analysis of cultural heritage 
materials [7]. Efforts have been devoted to develop hybrid setups based in a common pulsed laser source capable of in situ recording Raman, time-resolved remote LIF, and LIB spectra from the same spot of a substrate or of an object $[38,39]$. The results of those investigations have shown that a combination of time-resolved Raman and LIF spectroscopies with LIBS can be effectively used for detecting various types of phytopigment biomarkers on planetary surfaces. More recently, Osticioli et al. [40] have presented a compact instrument capable of recording Raman, LIB, and LIF spectra, with capacity to provide complementary information regarding the substrate chemical composition.

In this work, we present the analysis of heritage stones, alabaster, gypsum, limestone and marble, and model wall paintings based on a red pigment, with a hybrid system that allows acquisition of Raman, LIF and LIBS signals from the same sample spot using a single Q-Switched $\mathrm{Nd}$ :YAG laser delivering nanosecond pulses and operating at its second (532 nm), third (355 $\mathrm{nm}$ ) or fourth (266 nm) harmonics. We aim at the validation of the developed system and determination of the optimum excitation laser wavelength and detection parameters, including spectral and temporal ranges, allowing the identification of the type of minerals in the stone samples and the characterization of the pigment and binder composition in the wall paintings.

\section{Material and methods}

Measurements were performed with a laboratory, compact, hybrid Raman, LIF, LIBS setup that is schematized in Figure 1. It is based on the excitation of the three types of spectroscopic signals with a Q-Switched Nd:YAG laser (LS-2147, Lotis II) operating as mentioned at 532, 355 or $266 \mathrm{~nm}$ at a repetition rate of $10 \mathrm{~Hz}$, delivering pulses of $17 \mathrm{~ns}$ with Gaussian-like spatial profile. The linearly polarized laser beam is directed to the surface of the sample by means of dichroic mirrors at an incidence angle of $45^{\circ}$. For LIBS measurements, and to increase the laser fluence values above the ablation threshold of the material analysed, the laser beam is focused with a spherical plano-convex quartz lens (L1), with a focal length of $150 \mathrm{~mm}$, inserted in the beam path in front of the sample. A diaphragm (D) is used to control the size of the sample surface illuminated by the laser. The laser pulse energy can be varied with a variable dielectric attenuator (Laser Optik). The average pulse-to-pulse energy fluctuations are of the order of 10 $\%$. The laser spot size and pulse energy are adjusted to their lowest possible values, to achieve the maximum superficial resolution, to avoid sample damage and to obtain spectra with a high signal to noise ratio. Particularly for Raman and LIF, the laser spot diameter and the fluence value were of $2 \mathrm{~mm}$ and $20 \mathrm{~mJ} \mathrm{~cm}^{-2}$, respectively, for the three used wavelengths. For LIBS the 
laser spot diameter was $200 \mu \mathrm{m}$ for the three irradiation wavelengths and the fluence values were $6 \mathrm{~J} \mathrm{~cm}^{-2}$ for irradiation at 266 and $355 \mathrm{~nm}$, and $10 \mathrm{~J} \mathrm{~cm}^{-2}$ for irradiation at $532 \mathrm{~nm}$.

Raman, LIF and LIB spectra were acquired using a $0.30 \mathrm{~m}$ focal length spectrograph (TMc300, Bentham) equipped with two interchangeable diffraction gratings, both blazed at $500 \mathrm{~nm}$, with 1200 and 300 lines $\mathrm{mm}^{-1}$, providing a spectral coverage of 50 and $280 \mathrm{~nm}$, respectively in the 250-650 $\mathrm{nm}$ region. The spectrograph entrance slit width values were 50 and $500 \mu \mathrm{m}$, for the 1200 and 300 lines $\mathrm{mm}^{-1}$ diffraction gratings, respectively. The spectrograph is coupled to an ICCD (DH-501, Andor Technologies) operated in the gated mode by means of a digital delay/pulse generator (DG-535, Stanford Research Systems) providing a temporal resolution of 10 ns. The light emitted upon excitation is collected through a telescope, constituted by two lenses, L2 and L3 of 100 and $40 \mathrm{~mm}$ focal length respectively, and subsequently focused onto the spectrograph entrance slit. Each recorded spectrum in each spectroscopic modality results from the accumulation of 125 measurements collected from the same sample spot and summed up to provide good signal/noise ratios.

Raman and LIF spectra were recorded simultaneously exciting at 355 and $532 \mathrm{~nm}$, and a Notch filter at $355 \mathrm{~nm}$ when operating at this wavelength and a longpass edge filter at $532 \mathrm{~nm}$ when operating at this longer wavelength, were inserted in the collection optical path to reject laser light scattered from the samples. When LIF spectra were obtained by exciting at $266 \mathrm{~nm}$, and for long wavelength collection ( $>450 \mathrm{~nm}$ ), a $400 \mathrm{~nm}$ longpass filter was set at the entrance of the spectrograph to avoid the second-order of lower wavelength emissions and laser beam. For both Raman and LIF measurements, the ICCD was operated with a delay and gate width values of 0 and $50 \mathrm{~ns}$, respectively.

By irradiating in a different sample location to that chosen for recording Raman and LIF spectra, LIB spectra were acquired with a temporal gate of $3 \mu \mathrm{s}$, delayed by 500-1000 ns with respect to the arrival of the excitation laser pulse to the sample. As in the case of LIF measurements, for long wavelength collection, a $400 \mathrm{~nm}$ longpass filter was placed in front of the spectrograph to avoid the second-order of lower wavelength emissions and laser beam. The reproducibility of LIB spectra was checked by acquiring them in various sample position and craters of around 200-micron diameter were produced. 


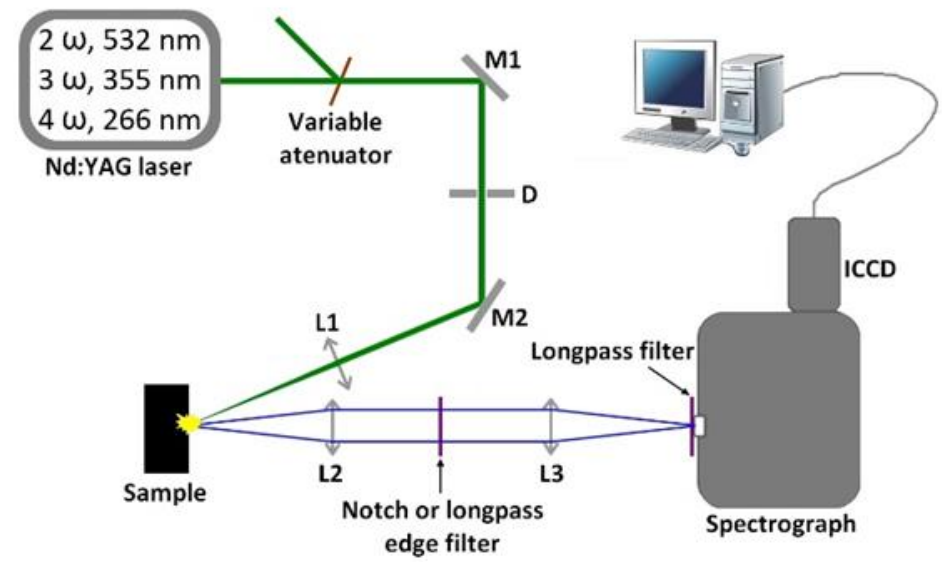

Figure 1. Scheme of the Raman-LIF-LIBS setup. M: mirror, D: Diaphragm, L: Lens, ICCD: intensified charge coupled device.

The heritage stone samples come from important historical buildings of Madrid, Spain. With typical sizes of about $5 \times 3 \times 1 \mathrm{~cm}^{3}$, they consist of two calcium sulphate dihydrate $\left(\mathrm{CaSO}_{4} \cdot 2 \mathrm{H}_{2} \mathrm{O}\right)$ based stones, alabaster and gypsum, and three calcium carbonate $\left(\mathrm{CaCO}_{3}\right)$ based stones, limestone, white and dark marble.

The model wall paintings are coupons of approximately $5 \times 5 \times 5 \mathrm{~cm}^{3}$ with a red pigment paint layer applied on a lime mortar substrate. Three coupons were prepared, each applying a different painting layer, one using the fresco technique, where the pigment is directly applied on fresh lime mortar without any binder, and two more, where the paint layer is a mixture of the same pigment with two different organic binders.

\section{Results and discussion}

\subsection{Heritage stone samples}

Figure 2 shows the simultaneously acquired Raman and LIF spectra of the heritage stone samples collected by laser excitation at 355 and $532 \mathrm{~nm}$ using the 1200 lines $\mathrm{mm}^{-1}$ grating. Spectra corresponding to the dark marble sample (not shown) are very similar to those obtained from the white marble, although their intensity is much lower.

As observed in Figure 2, excitation at $355 \mathrm{~nm}$ allows the detection of LIF emissions from all stone samples. However, by excitation at $532 \mathrm{~nm}$, fluorescence bands are only observed from gypsum and limestone. Regarding Raman spectra, excitation at $532 \mathrm{~nm}$ allows the measurement of bands with Raman shift values above $150 \mathrm{~cm}^{-1}$, while excitation at $355 \mathrm{~nm}$ restricts the collection of Raman spectra to the region above $1000 \mathrm{~cm}^{-1}$. At this shorter 
excitation wavelength, some of the Raman bands are partially overlapped by the intense LIF emissions.

For each stone sample the observed Raman bands were readily assigned (Table 1). Upon excitation at 355 and $532 \mathrm{~nm}$ of alabaster and gypsum, vibrational bands are observed at 197, $313,415,494,619,671,1008$ and $1135 \mathrm{~cm}^{-1}$, corresponding to the Raman active modes of $\mathrm{SO}_{4}{ }^{2-}$ [41], and at 3200 and $3440 \mathrm{~cm}^{-1}$ due to the symmetric and anti-symmetric stretching modes of the $\mathrm{O}-\mathrm{H}$ groups of water [41]. For limestone and marble, bands observed at 154, $281,711,1085,1445$ and $1744 \mathrm{~cm}^{-1}$ are assigned to the Raman active modes of $\mathrm{CO}_{3}{ }^{2-}$ [42]. The last two Raman bands can also can also have contribution of bands assigned to organic residues [36], (1445 $\mathrm{cm}^{-1}$ to $\mathrm{CH}$ and $\mathrm{CH}_{3}$ and $1744 \mathrm{~cm}^{-1}$ to $\mathrm{C}=0$ ). Thus, the Raman spectral analysis serves to group the stone samples in two mineral categories, corresponding to sulphates, alabaster and gypsum, and to carbonates, limestone and marble.

Further discrimination among the samples is achieved through the analysis of LIF spectra. Excitation at $355 \mathrm{~nm}$, induces a broad emission in the 360 to $650 \mathrm{~nm}$ region for all five samples. The observed broad fluorescence can be attributed to overlapping bands of trace transition and rare-earth metal ions in the mineral lattices and can also include contributions of trapped electrons and organic material, such as bitumen and carotenes [43-46]. The presence of peaks of organic origin in the Raman spectra of these materials as discussed above, supports such assignment. In alabaster, an intense fluorescence band in the 360-450 $\mathrm{nm}$ region and centred around $382 \mathrm{~nm}$ appears overimposed on the described broad fluorescence. Assignment of this bluish fluorescence is not straightforward, although it is most probably due to organic impurities related with the presence of humic acids, the major organic compounds found in soils [47]. Therefore, the distinct LIF emissions of alabaster and gypsum allow differentiation among these two sulphate-based materials. On the contrary, the differentiation between the two carbonates, limestone and marble, cannot be made in base of their $355 \mathrm{~nm}$ LIF spectra, as those are rather similar. Nevertheless, for LIF spectra recorded by exciting at $532 \mathrm{~nm}$, the fluorescence emission band of marble is absent, and then, the two carbonate minerals are clearly distinguishable.

LIB spectra were recorded in the stone samples by laser irradiation at 355 and $532 \mathrm{~nm}$ with the 1200 lines $\mathrm{mm}^{-1}$ diffraction grating, yielding the same emission lines at both wavelengths. As an example, Figure 3 shows the spectrum obtained in gypsum at $355 \mathrm{~nm}$, and reveals the elemental composition of the sample according to the emission lines of the main and minor components (Table 1). Spectra of all samples display mainly atomic emissions of $\mathrm{Ca}, \mathrm{Na}, \mathrm{Mn}$ and $\mathrm{Sr}$ and broader molecular emissions of $\mathrm{CN}$ (Violet system), $\mathrm{C}_{2}$ (Swan bands) and $\mathrm{CaO}$ (Green, $550 \mathrm{~nm}$, and Orange, $610 \mathrm{~nm}$, systems). Discriminating stone materials on the basis of 
their elemental composition is not a straightforward task, because most of stone samples contain calcium and sulphur based minerals, resulting in spectra with quite similar emission features [12] and references therein. The most intense lines correspond in all samples to $\mathrm{Ca}$, as expected due to the composition of the base mineral of alabaster and gypsum, calcium sulphate, and of that of limestone and marble, calcium carbonate. Sulphur cannot be detected with the presented system because S can be only detected by LIBS either in the VUV (182.6 $\mathrm{nm}$ ) or in the IR part of the spectrum. Together with these common emission features, lines of $\mathrm{Mg}, \mathrm{Si}, \mathrm{Al}$ and $\mathrm{K}$ are found in the spectra of the gypsum sample, of $\mathrm{Mg}$ in the spectra of limestone and white marble and of $\mathrm{Mg}$ and $\mathrm{Al}$ in the spectra of dark marble. $\mathrm{Mn}, \mathrm{Mg}$ and $\mathrm{Sr}$ are often components of stone samples based on calcium and magnesium carbonates, with the addition of strontium and manganese, whereas Al and Si normally are present as oxides or silicate impurities [12] and references therein. The presence of CN and C2 in all the samples can be due to ambient contamination in the storage process. 


$$
\lambda_{\mathrm{EXC}}=355 \mathrm{~nm}
$$

$\lambda_{\mathrm{EXC}}=532 \mathrm{~nm}$

Raman shift/ $\mathrm{cm}^{-1}$ Alabaster Raman shift/ $\mathrm{cm}^{-1}$
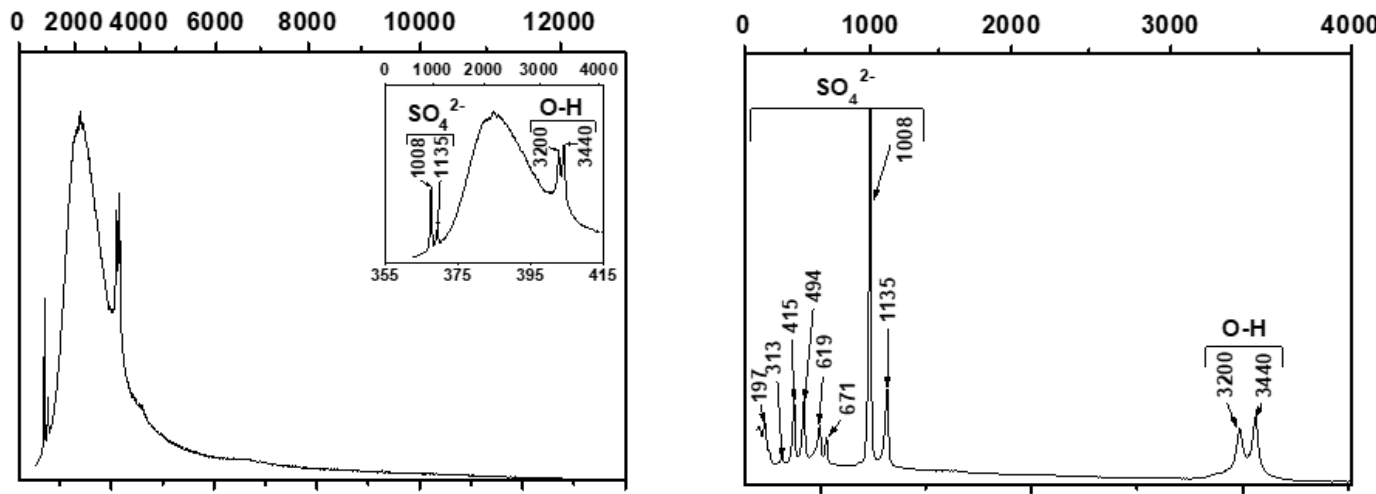

Gypsum
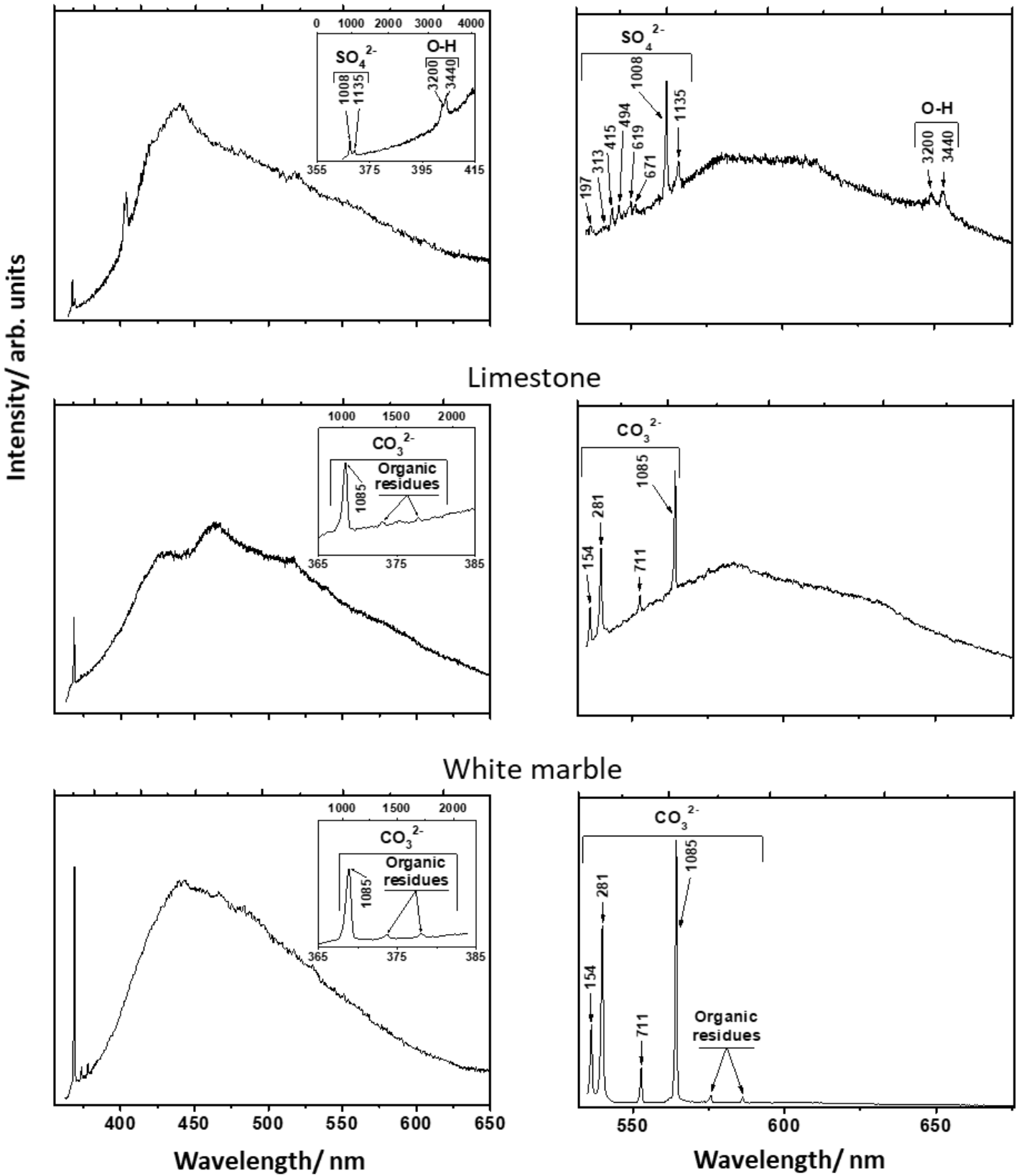

imestone

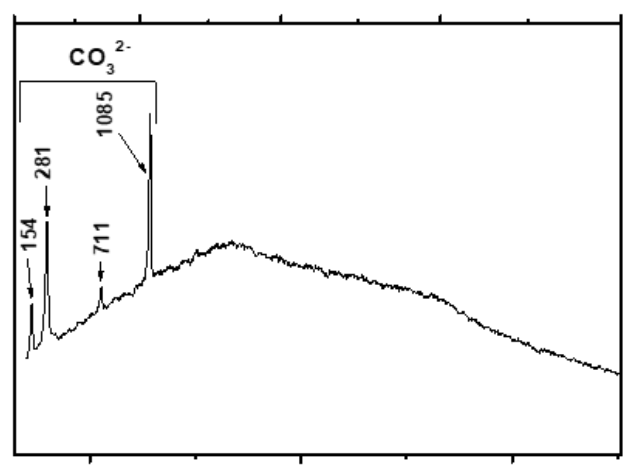

White marble

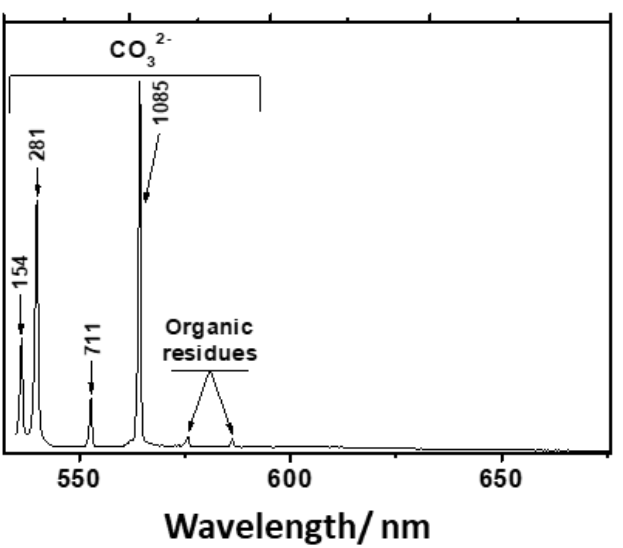

Figure 2. Raman and LIF spectra of stone samples excited at $355 \mathrm{~nm}$ (left) and $532 \mathrm{~nm}$ (right). Raman bands are indicated in $\mathrm{cm}^{-1}$. 


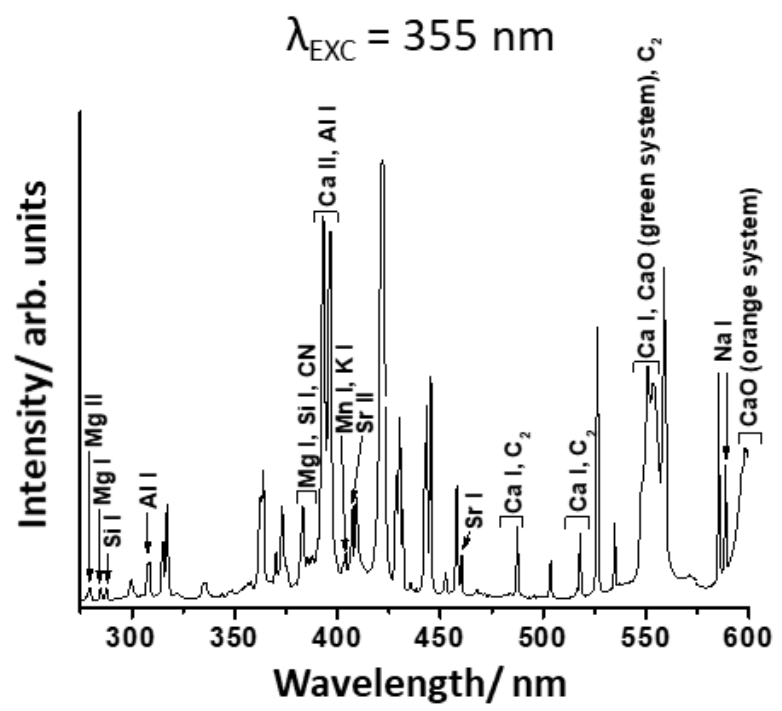

Figure 3. LIB spectrum of the gypsum sample recorded at $355 \mathrm{~nm}$. The non-labelled lines are assigned to Ca.

Table 1 lists the Raman, LIF and LIBS emissions collected on the stone samples and summarizes the assignments discussed above.

Table 1. Elemental and molecular information of heritage stone samples determined by Raman, LIF and LIB spectroscopies. Raman and LIF spectra were obtained under 355 and $532 \mathrm{~nm}$ excitation and LIB spectra under $355 \mathrm{~nm}$ irradiation.

\begin{tabular}{|c|c|c|c|}
\hline $\begin{array}{c}\text { Stone } \\
\text { sample }\end{array}$ & Raman bands $\left(\mathrm{cm}^{-1}\right)$ & LIF bands (nm) & LIBS lines \\
\hline Alabaster & \multirow{2}{*}{$\begin{array}{c}197,313,415,494,619 \\
671,1008 \text { and } 1135\left(\mathrm{SO}_{4}{ }^{2-}\right) \\
3200 \text { and } 3440(\mathrm{O}-\mathrm{H})\end{array}$} & $\begin{array}{l}\text { 360-450 (humic acids) } \\
\text { 360-650 (trapped electrons, } \\
\text { rare-earths and organic } \\
\text { materials: bitumen, carotenes) }\end{array}$ & $\begin{array}{c}\mathrm{Ca}, \mathrm{Na}, \mathrm{Mn}, \mathrm{Sr}, \mathrm{CN} \text { (Violet } \\
\text { system), } \mathrm{C}_{2} \text { (Swan bands), } \mathrm{CaO} \\
\text { (Green and Orange systems) }\end{array}$ \\
\hline Gypsum & & $\begin{array}{l}\text { 360-650 (trapped electrons, } \\
\text { rare-earths and organic } \\
\text { materials: bitumen, carotenes) }\end{array}$ & $\begin{array}{c}\mathrm{Ca}, \mathrm{Na}, \mathrm{Mn}, \mathrm{Sr}, \mathrm{CN} \text { (Violet } \\
\text { system), } \mathrm{C}_{2} \text { (Swan bands), } \mathrm{CaO} \\
\text { (Green and Orange systems), Mg, } \\
\mathrm{Si}, \mathrm{Al}, \mathrm{K}\end{array}$ \\
\hline Limestone & \multirow{3}{*}{$\begin{array}{l}154,281,711,1085,1455 \\
\text { and } 1744\left(\mathrm{CO}_{3}{ }^{2-}\right) \\
1455\left(\mathrm{CH}, \mathrm{CH}_{3}\right) \text { and } 1744 \\
(\mathrm{C}=\mathrm{O}) \text { (organic residues) }\end{array}$} & \multirow{3}{*}{$\begin{array}{l}\text { 360-650 (trapped electrons, } \\
\text { rare-earths and organic } \\
\text { materials: bitumen, carotenes) }\end{array}$} & $\begin{array}{c}\mathrm{Ca}, \mathrm{Na}, \mathrm{Mn}, \mathrm{Sr}, \mathrm{CN} \text { (Violet } \\
\text { system), } \mathrm{C}_{2} \text { (Swan bands), } \mathrm{CaO} \\
\text { (Green and Orange systems), Mg }\end{array}$ \\
\hline $\begin{array}{l}\text { White } \\
\text { marble }\end{array}$ & & & $\begin{array}{c}\mathrm{Ca}, \mathrm{Na}, \mathrm{Mn}, \mathrm{Sr}, \mathrm{CN} \text { (Violet } \\
\text { system), } \mathrm{C}_{2} \text { (Swan bands), } \mathrm{CaO} \\
\text { (Green and Orange systems), Mg }\end{array}$ \\
\hline $\begin{array}{c}\text { Dark } \\
\text { marble }\end{array}$ & & & $\begin{array}{c}\mathrm{Ca}, \mathrm{Na}, \mathrm{Mn}, \mathrm{Sr}, \mathrm{CN} \text { (Violet } \\
\text { system), } \mathrm{C}_{2} \text { (Swan bands), CaO } \\
\text { (Green and Orange systems), Mg, } \\
\text { Al }\end{array}$ \\
\hline
\end{tabular}




\subsection{Model wall paintings}

Raman spectra of the model wall paintings were collected by laser excitation at $532 \mathrm{~nm}$, using the 1200 lines $\mathrm{mm}^{-1}$ diffraction grating. This excitation wavelength allows better Raman resolution and diminishes fluorescence. Figure 4a shows the Raman spectra of the fresco sample, in both the pigment side (red line) and in the base mortar (black line). Bands at 281 and $1085 \mathrm{~cm}^{-1}$ correspond to calcite $\left(\mathrm{CaCO}_{3}\right)$ and that at $465 \mathrm{~cm}^{-1}$ is due to quartz $\left(\alpha-\mathrm{SiO}_{2}\right)$. The intensity of the Raman signal of the pigment side of the sample is extremely low, although several weak bands are detected, including those of the substrate, at 281, 465 and $1085 \mathrm{~cm}^{-1}$. An additional band at $253 \mathrm{~cm}^{-1}$ is tentatively assigned to $\mathrm{HgS}$, constituent of the pigment red vermillion [48] (Table 2), the only red pigment with mercury in its composition. The samples prepared as mixtures of the pigment with two different organic binders did not yield any measurable Raman signal.

LIF spectra of the model wall paintings, shown in Figure $4 \mathrm{~b}$, were measured by excitation at $266 \mathrm{~nm}$ using the diffraction grating of 300 lines $\mathrm{mm}^{-1}$. This excitation wavelength was chosen in order to extend towards the UV the spectral range where fluorescence from organic compounds present in the samples could be detected [3]. A common main broad band appears in the 300 to $650 \mathrm{~nm}$ range and is assigned to lime compounds $\left(\mathrm{CaO}, \mathrm{Ca}(\mathrm{OH})_{2}\right)$ of the mortar substrate [36]. For the three model paint samples an additional band over imposed on the broad fluorescence in the region of $610 \mathrm{~nm}$ is attributed to luminescence of the HgS semiconductor $[49,50]$ and, together with the previous observation by Raman, allows the identification of the red pigment as vermillion. The fluorescence signal detected from the fresco sample (red line) presents a maximum around $433 \mathrm{~nm}$. In the spectrum of the mixture of the pigment with binder 1 (black line), the main fluorescence band is shifted to longer wavelengths (with a maximum around $470 \mathrm{~nm}$ ) with respect to the fresco sample. This shift suggests a contribution from the binder, which can be assigned to linseed oil $[3,35,36]$. The sample prepared using the pigment in a mixture with binder 2 (blue line) presents a much higher fluorescence signal than the fresco sample, and in this case, a new band centred at 333 $\mathrm{nm}$ is observed together with the two bands previously mentioned. This band can be assigned to tryptophan (Trp), a fluorescent amino acid present in proteins $[3,35]$, suggesting the use of egg yolk as binder 2. Also for binder 2, the main broad band is shifted to longer wavelengths (maximum at $455 \mathrm{~nm}$ ), in relation with the maximum of the fresco sample, probably due to the presence of egg yolk $[3,35,36]$. 

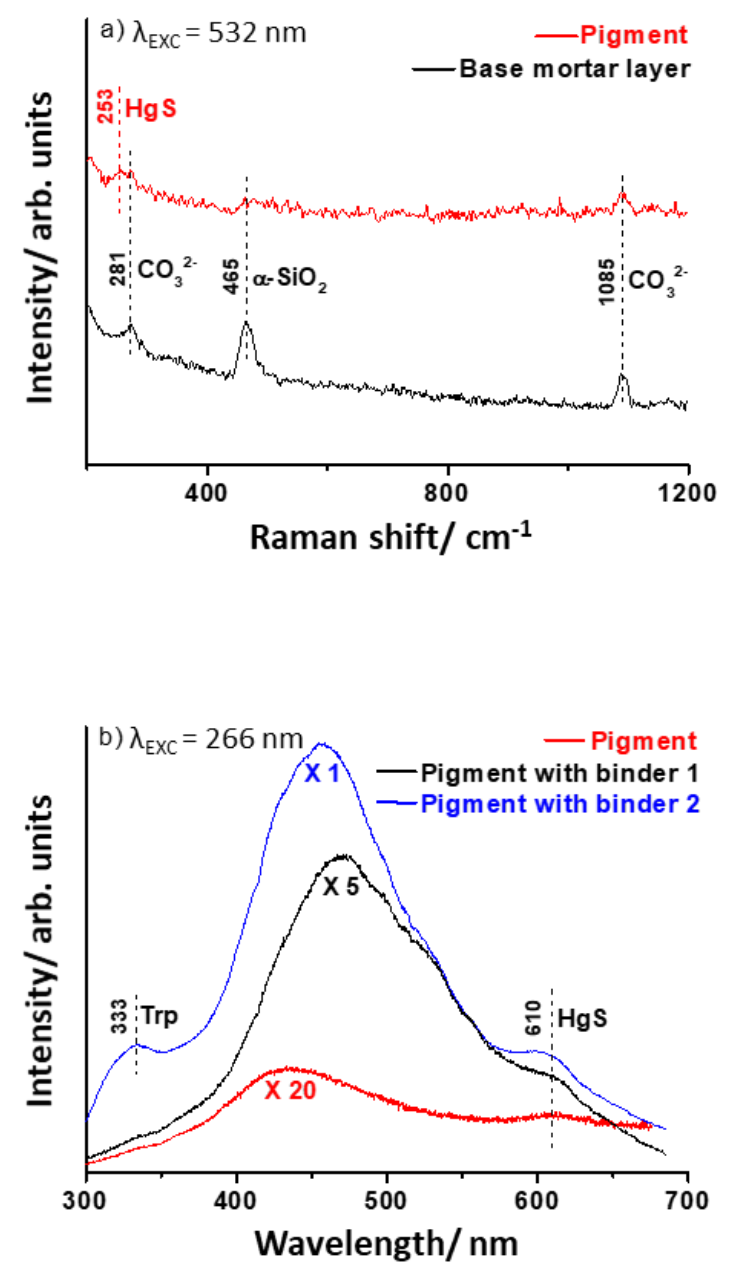

Figure 4. a) Raman spectra collected by excitation at $532 \mathrm{~nm}$ of fresco sample and b) LIF spectra of the model wall paints obtained at $266 \mathrm{~nm}$. Vertical dotted lines indicate assignment of the Raman and LIF bands. The multiplication factor is indicated in each spectrum.

LIB spectra of the model wall paintings were recorded on the paint and mortar sides of the substrate by irradiation at $266 \mathrm{~nm}$, a wavelength which has been found optimum for LIBS analysis of this type of samples [21]. All these spectra were obtained with the diffraction grating of 1200 lines $\mathrm{mm}^{-1}$. Atomic spectral lines are assigned to $\mathrm{Mg}, \mathrm{Ca}, \mathrm{Si}, \mathrm{C}, \mathrm{Al}, \mathrm{Na}, \mathrm{K}, \mathrm{Sr}$, while molecular bands are due to CN (Violet band), $C_{2}$ (Swan bands) and $\mathrm{CaO}$ (Green and Orange systems) (Table 2). These components are probably related to organic residues and carbonate from the base mortar substrate and to the organic binders. The most intense lines correspond to $\mathrm{Ca}$, due to the presence of calcium carbonate, as observed by Raman spectroscopy, and lime. As an example, the LIB spectrum of the fresco sample is showed in Figure 5. In this case, additional $\mathrm{Hg}$ lines are also evident, confirming the elemental composition of the red vermillion pigment. In the LIB spectra of samples corresponding to the 
pigment and binder mixtures (not shown), the molecular bands are more intense due to the organic binders.
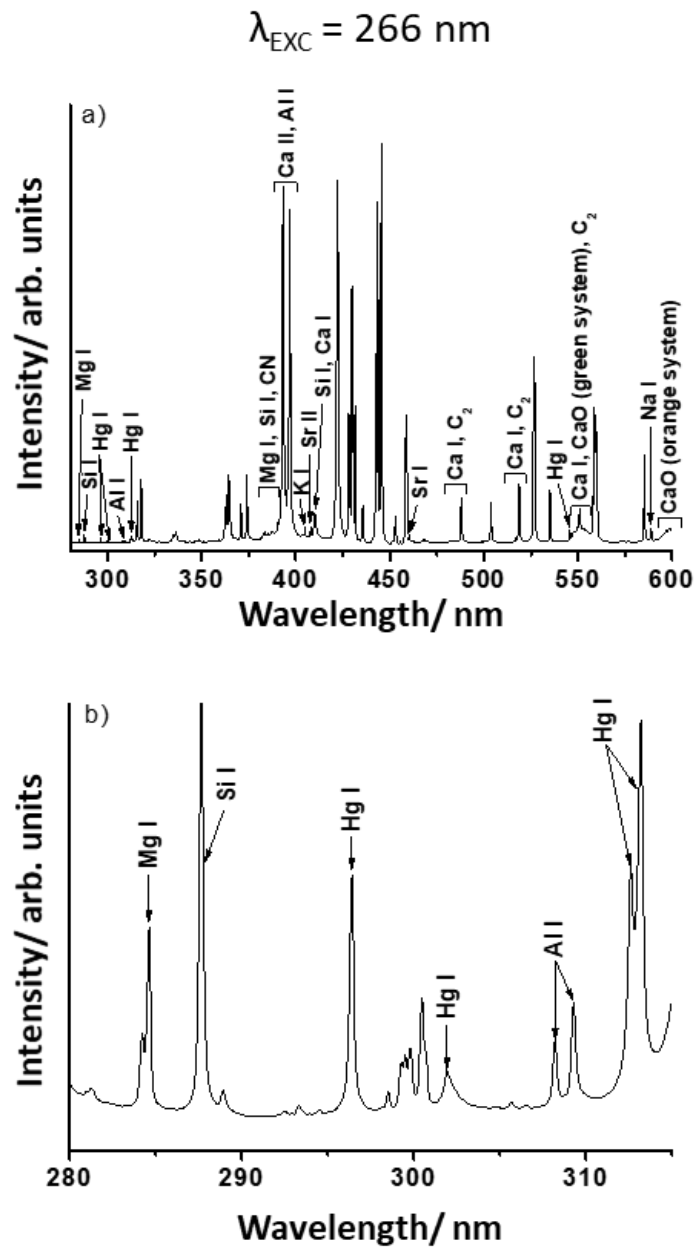

Figure 5. a) LIB spectra of the fresco model wall paint under $266 \mathrm{~nm}$ excitation. b) Spectrum shown with more detail in the 280-315 region. The non-labelled lines are assigned to $\mathrm{Ca}$.

Table 2 lists the bands and summarizes the elemental and molecular information obtained from the model wall paintings by Raman, LIF and LIBS measurements.

Table 2. Elemental and molecular information of wall model paintings determined by Raman, LIB and LIF spectroscopies. Raman spectra were obtained under $532 \mathrm{~nm}$ excitation and LIF and LIB spectra under $266 \mathrm{~nm}$ excitation.

\begin{tabular}{|c|c|c|c|}
\hline Sample & Raman bands $\left(\mathrm{cm}^{-1}\right)$ & LIF bands maxima $(\mathrm{nm})$ & LIBS lines \\
\hline $\begin{array}{l}\text { Fresco } \\
\text { paint }\end{array}$ & $\begin{array}{c}253(\mathrm{HgS}) \\
281 \text { and } 1085\left(\mathrm{CaCO}_{3}\right) \\
449\left(\alpha-\mathrm{SiO}_{2}\right)\end{array}$ & $\begin{array}{c}433\left(\mathrm{CaO}, \mathrm{Ca}(\mathrm{OH})_{2}\right) \\
610(\mathrm{HgS})\end{array}$ & \multirow{3}{*}{$\begin{array}{c}\mathrm{Hg}, \mathrm{Mg}, \mathrm{Ca}, \mathrm{Si}, \mathrm{C}, \mathrm{Al}, \mathrm{Na}, \mathrm{K}, \mathrm{Sr} \text {, } \\
\mathrm{CN} \text { (Violet system), C2 (Swan } \\
\text { bands), } \mathrm{CaO} \text { (Green and } \\
\text { Orange systems) }\end{array}$} \\
\hline $\begin{array}{l}\text { Pigment + } \\
\text { binder } 1\end{array}$ & - & $\begin{array}{c}470\left(\mathrm{CaO}, \mathrm{Ca}(\mathrm{OH})_{2}+\text { linseed oil }\right) \\
610(\mathrm{HgS})\end{array}$ & \\
\hline $\begin{array}{l}\text { Pigment + } \\
\text { binder } 2\end{array}$ & - & $\begin{array}{c}333 \text { (Tryptophan) } \\
455\left(\mathrm{CaO}, \mathrm{Ca}(\mathrm{OH})_{2}+\text { egg yolk) }\right. \\
610(\mathrm{HgS})\end{array}$ & \\
\hline Mortar & 174,281 and 1087 & $433\left(\mathrm{CaO}, \mathrm{Ca}(\mathrm{OH})_{2}\right)$ & $\mathrm{Mg}, \mathrm{Ca}, \mathrm{Si}, \mathrm{C}, \mathrm{Al}, \mathrm{Na}, \mathrm{K}, \mathrm{Sr}, \mathrm{CN}$ \\
\hline
\end{tabular}




\begin{tabular}{|c|c|c|c|}
\hline substrate & $\begin{array}{c}\left(\mathrm{CaCO}_{3}\right) \\
449\left(\text { quartz, } \alpha-\mathrm{SiO}_{2}\right)\end{array}$ & $\begin{array}{c}\text { (Violet system), } \mathrm{C} 2 \text { (Swan } \\
\text { bands), } \mathrm{CaO} \text { (Green and } \\
\text { Orange systems) }\end{array}$ \\
\hline
\end{tabular}

As described, the results presented herein show how the system used working in the three spectroscopic modalities of Raman, LIF and LIBS and based in Nd:YAG laser harmonic emission and signal acquisition with time resolution, is capable to identify the composition of heritage stone samples and the paint materials in model wall paintings. A similar system as the one presented here [40], and based on the excitation wavelengths of 532 and $266 \mathrm{~nm}$, has been shown to reveal the constituent materials of painting substrates. The possibility to combine the three Nd:YAG laser wavelengths of 532, 355 and $266 \mathrm{~nm}$, as in the present work, widens the analytical capabilities of such a hybrid approach and enlarges the range of applications to a larger variety of cultural heritage substrates. The next step working with this experimental setup is to use its capability of performing measurements of time-resolved fluorescence, which provides useful information of the fluorescence origin [51], and allows the identification of inorganic and organic materials in cultural heritage.

\section{Conclusions}

In this study we have shown that a laboratory, hybrid system based on the pulsed laser excitation of Raman, laser-induced fluorescence and laser-induced breakdown spectroscopy signals serves for material identification in stone and wall paint samples, of relevance as cultural heritage substrates. By using a single, compact setup based in excitation with nanosecond pulses of a Q-switched Nd:YAG laser, we determined the best combination of excitation wavelengths $(532,355,266 \mathrm{~nm})$ and spectral and temporal ranges for signal acquisition, that allowed us to identify the type of minerals in stone samples and of the pigment and binder composition in model wall paintings. Particularly, temporally gated Raman spectroscopy has served to differentiate sulphate-based stones from those of carbonate composition. Bands corresponding to the sulphate ion and the $\mathrm{O}-\mathrm{H}$ group of water have been observed for alabaster and gypsum, while bands corresponding to the carbonate ion and to organic residues were detected for limestone and marble. On the other hand, analysis of laser induced fluorescence upon $355 \mathrm{~nm}$ excitation provided further information about the nature of the organic residues, indicating the presence of humic acids, in the case of alabaster, and of bitumen and carotenes in the case of gypsum, limestone and marble. Finally, LIBS has revealed the sample elemental constituents and the presence of molecular $\mathrm{CN}, \mathrm{C}_{2}$ and $\mathrm{CaO}$ species that confirm the presence of organic compounds, as indicated by Raman and LIF spectra. For the model wall paintings, Raman, LIF and LIBS results corroborated the nature of the lime mortar substrate and allowed identification of the pigment as red vermillion (HgS), by virtue of the $\mathrm{Hg}$ atomic lines in the LIB spectra and of a molecular band in the LIF spectra. In the case of the 
fresco sample, the Raman spectra also showed a weak, but clearly distinguishable $\mathrm{HgS}$ band. For paint samples consisting in a mixture of pigment with two different binders, LIF spectra gave sufficient indication of the presence of linseed oil and egg yolk. The measurements, totally non-destructive or, as in the case of LIBS, minimally affecting the surface, were performed directly on the samples under study without any previous preparation. The results of this work are part of an integrated effort to contribute to further development of compact, transportable prototypes for measurement campaigns for field analysis of samples and objects of the cultural heritage.

\section{Acknowledgments}

This work has been funded by EU project "Integrated Platform for the European Research Infrastructure on Cultural Heritage" (IPERION-CH, Ref. H2020-INFRAIA-2014-2015, GRANT n 654028) and by program GEOMATERIALES 2-CM (S2013/MIT_2914) from the Community of Madrid. M. O. thanks CSIC for a contract.

\section{References}

[1] D. Anglos, Laser-Induced Breakdown Spectroscopy in Art and Archaeology, Applied Spectroscopy, 55 (2001) 186A-205A.

[2] D. Anglos, V. Detalle, Cultural Heritage Applications of LIBS, in: S. Musazzi, U. Perini (Eds.) Laser-Induced Breakdown Spectroscopy: Theory and Applications, Springer Berlin Heidelberg, Berlin, Heidelberg, 2014, pp. 531-554.

[3] A. Nevin, G. Spoto, D. Anglos, Laser spectroscopies for elemental and molecular analysis in art and archaeology, Appl. Phys. A, 106 (2012) 339-361.

[4] D.A. Cremers, A.K. Knight, Laser-Induced Breakdown Spectroscopy, Wiley Online Library, 2006.

[5] D.W. Hahn, N. Omenetto, Laser-Induced Breakdown Spectroscopy (LIBS), Part II: Review of Instrumental and Methodological Approaches to Material Analysis and Applications to Different Fields, Applied Spectroscopy, 66 (2012) 347-419.

[6] E. Tognoni, V. Palleschi, M. Corsi, G. Cristoforetti, Quantitative micro-analysis by laserinduced breakdown spectroscopy: a review of the experimental approaches, Spectrochimica Acta Part B: Atomic Spectroscopy, 57 (2002) 1115-1130.

[7] M. Castillejo, M. Martín, M. Oujja, D. Silva, R. Torres, C. Domingo, J.V. García-Ramos, S. Sánchez-Cortés, Spectroscopic Analysis of Pigments and Binding Media of Polychromes by the Combination of Optical Laser-Based and Vibrational Techniques, Applied Spectroscopy, 55 (2001) 992-998.

[8] P. Vandenabeele, H.G.M. Edwards, L. Moens, A Decade of Raman Spectroscopy in Art and Archaeology, Chemical Reviews, 107 (2007) 675-686.

[9] F. Casadio, C. Daher, L. Bellot-Gurlet, Raman Spectroscopy of Cultural Heritage Materials: Overview of Applications and New Frontiers in Instrumentation, Sampling Modalities, and Data Processing, Topics in Current Chemistry, 374 (2016) 62.

[10] M. Oujja, M. Sanz, F. Agua, J.F. Conde, M. Garcia-Heras, A. Davila, P. Onate, J. Sanguino, J.R. Vazquez de Aldana, P. Moreno, M.A. Villegas, M. Castillejo, Multianalytical characterization 
of Late Roman glasses including nanosecond and femtosecond laser induced breakdown spectroscopy, Journal of Analytical Atomic Spectrometry, 30 (2015) 1590-1599.

[11] K. Melessanaki, M. Mateo, S.C. Ferrence, P.P. Betancourt, D. Anglos, The application of LIBS for the analysis of archaeological ceramic and metal artifacts, Appl. Surf. Sci., 197 (2002) 156-163.

[12] A. Giakoumaki, K. Melessanaki, D. Anglos, Laser-induced breakdown spectroscopy (LIBS) in archaeological science-applications and prospects, Analytical and Bioanalytical Chemistry, 387 (2007) 749-760.

[13] M. Castillejo, M. Martín, D. Silva, T. Stratoudaki, D. Anglos, L. Burgio, R.J.H. Clark, Analysis of pigments in polychromes by use of laser induced breakdown spectroscopy and Raman microscopy, Journal of Molecular Structure, 550 (2000) 191-198.

[14] L. Burgio, R.J.H. Clark, T. Stratoudaki, M. Doulgeridis, D. Anglos, Pigment Identification in Painted Artworks: A Dual Analytical Approach Employing Laser-Induced Breakdown

Spectroscopy and Raman Microscopy, Applied Spectroscopy, 54 (2000) 463-469.

[15] R. Bruder, V. Detalle, C. Coupry, An example of the complementarity of laser-induced breakdown spectroscopy and Raman microscopy for wall painting pigments analysis, J. Raman Spectroc., 38 (2007) 909-915.

[16] M. Bicchieri, M. Nardone, P. Russo, A. Sodo, M. Corsi, G. Cristoforetti, V. Palleschi, A. Salvetti, E. Tognoni, Characterization of azurite and lazurite based pigments by laser induced breakdown spectroscopy and micro-Raman spectroscopy, Spectrochimica Acta Part B: Atomic Spectroscopy, 56 (2001) 915-922.

[17] I. Osticioli, N.F.C. Mendes, A. Nevin, F.P.S.C. Gil, M. Becucci, E. Castellucci, Analysis of natural and artificial ultramarine blue pigments using laser induced breakdown and pulsed Raman spectroscopy, statistical analysis and light microscopy, Spectrochimica Acta Part A: Molecular and Biomolecular Spectroscopy, 73 (2009) 525-531.

[18] P.P. Yaney, The pulsed laser and gated detection in Raman spectroscopy - a survey of the spectra of common substances including studies of adsorbed benzene, J. Raman Spectroc., 5 (1976) 219-241.

[19] N. Everall, R.W. Jackson, J. Howard, K. Hutchinson, Fluorescence rejection in Raman spectroscopy using a gated intensified diode array detector, J. Raman Spectroc., 17 (1986) 415423.

[20] A.K. Misra, S.K. Sharma, C.H. Chio, P.G. Lucey, B. Lienert, Pulsed remote Raman system for daytime measurements of mineral spectra, Spectrochimica Acta Part A: Molecular and Biomolecular Spectroscopy, 61 (2005) 2281-2287.

[21] X. Bai, D. Syvilay, N. Wilkie-Chancellier, A. Texier, L. Martinez, S. Serfaty, D. Martos-Levif, V. Detalle, Influence of ns-laser wavelength in laser-induced breakdown spectroscopy for discrimination of painting techniques, Spectrochimica Acta Part B: Atomic Spectroscopy, 134 (2017) 81-90.

[22] A. Giakoumaki, I. Osticioli, D. Anglos, Spectroscopic analysis using a hybrid LIBS-Raman system, Appl. Phys. A, 83 (2006) 537-541.

[23] I. Osticioli, N.F.C. Mendes, S. Porcinai, A. Cagnini, E. Castellucci, Spectroscopic analysis of works of art using a single LIBS and pulsed Raman setup, Analytical and Bioanalytical Chemistry, 394 (2009) 1033-1041.

[24] L. Ancillotti, E.M. Castellucci, M. Becucci, A combined Raman-LIBS spectrometer: toward a mobile atomic and molecular analytical tool for in situ applications, in: Proceedings of SPIE 5850, 2005, pp. 182-189.

[25] Z.E. Papliaka, A. Philippidis, P. Siozos, M. Vakondiou, K. Melessanaki, D. Anglos, A multitechnique approach, based on mobile/portable laser instruments, for the in situ pigment characterization of stone sculptures on the island of Crete dating from Venetian and Ottoman period, Heritage Science, 4 (2016).

[26] J. Moros, J.A. Lorenzo, P. Lucena, L. Miguel Tobaria, J.J. Laserna, Simultaneous Raman Spectroscopy-Laser-Induced Breakdown Spectroscopy for Instant Standoff Analysis of Explosives Using a Mobile Integrated Sensor Platform, Analytical Chemistry, 82 (2010) 13891400. 
[27] M. Hoehse, D. Mory, S. Florek, F. Weritz, I. Gornushkin, U. Panne, A combined laserinduced breakdown and Raman spectroscopy Echelle system for elemental and molecular microanalysis, Spectrochimica Acta Part B: Atomic Spectroscopy, 64 (2009) 1219-1227. [28] S.K. Sharma, A.K. Misra, P.G. Lucey, R.C. Wiens, S.M. Clegg, Combined remote LIBS and Raman spectroscopy at $8.6 \mathrm{~m}$ of sulfur-containing minerals, and minerals coated with hematite or covered with basaltic dust, Spectrochimica Acta Part A: Molecular and Biomolecular Spectroscopy, 68 (2007) 1036-1045.

[29] R.C. Wiens, S.K. Sharma, J. Thompson, A. Misra, P.G. Lucey, Joint analyses by laser-induced breakdown spectroscopy (LIBS) and Raman spectroscopy at stand-off distances,

Spectrochimica Acta Part A: Molecular and Biomolecular Spectroscopy, 61 (2005) 2324-2334.

[30] A. Del Bianco, I. Rauschenbach, V. Lazic, E. Jessberger, GENTNER-a miniaturised LIBS/Raman instrument for the comprehensive in situ analysis of the Martian surface, in: 4th NASA International Planetary Probe Workshop, 2006.

[31] C.B. Dreyer, G.S. Mungas, P. Thanh, J.G. Radziszewski, Study of sub-mJ-excited laserinduced plasma combined with Raman spectroscopy under Mars atmosphere-simulated conditions, Spectrochimica Acta Part B: Atomic Spectroscopy, 62 (2007) 1448-1459.

[32] E.C. Laan, B. Ahlers, W. Van Westrenen, J. Heiligers, A. Wielders, Moon4You: a combined Raman/LIBS instrument for lunar exploration, SPIE Optical Engineering+ Applications, (2009) 744114.

[33] Q. Lin, G. Niu, Q. Wang, Q. Yu, Y. Duan, Combined Laser-Induced Breakdown with Raman Spectroscopy: Historical Technology Development and Recent Applications, Applied Spectroscopy Reviews, 48 (2013) 487-508.

[34] A. Romani, C. Clementi, C. Miliani, G. Favaro, Fluorescence Spectroscopy: A Powerful Technique for the Noninvasive Characterization of Artwork, Accounts of Chemical Research, 43 (2010) 837-846.

[35] A. Nevin, D. Comelli, G. Valentini, R. Cubeddu, Total Synchronous Fluorescence Spectroscopy Combined with Multivariate Analysis: Method for the Classification of Selected Resins, Oils, and Protein-Based Media Used in Paintings, Analytical Chemistry, 81 (2009) 17841791.

[36] M. Oujja, C. Vázquez-Calvo, M. Sanz, M.Á. de Buergo, R. Fort, M. Castillejo, Laser-induced fluorescence and FT-Raman spectroscopy for characterizing patinas on stone substrates, Analytical and Bioanalytical Chemistry, 402 (2012) 1433-1441.

[37] B.J. Bozlee, A.K. Misra, S.K. Sharma, M. Ingram, Remote Raman and fluorescence studies of mineral samples, Spectrochimica Acta Part A: Molecular and Biomolecular Spectroscopy, 61 (2005) 2342-2348.

[38] S.K. Sharma, New trends in telescopic remote Raman spectroscopic instrumentation, Spectrochimica Acta Part A: Molecular and Biomolecular Spectroscopy, 68 (2007) 1008-1022. [39] M.N. Abedin, A.T. Bradley, S.K. Sharma, A.K. Misra, P.G. Lucey, C.P. McKay, S. Ismail, S.P. Sandford, Mineralogy and astrobiology detection using laser remote sensing instrument, Applied Optics, 54 (2015) 7598-7611.

[40] I. Osticioli, N.F.C. Mendes, A. Nevin, A. Zoppi, C. Lofrumento, M. Becucci, E.M. Castellucci, A new compact instrument for Raman, laser-induced breakdown, and laser-induced fluorescence spectroscopy of works of art and their constituent materials, Review of Scientific Instruments, 80 (2009) 076109.

[41] B.J. Berenblut, P. Dawson, G.R. Wilkinson, A comparison of the Raman spectra of anhydrite $\left(\mathrm{CaSO}_{4}\right)$ and gypsum $\left.\left(\mathrm{CaSO}_{4}\right) \cdot 2 \mathrm{H}_{2} \mathrm{O}\right)$, Spectrochimica Acta Part A: Molecular Spectroscopy, 29 (1973) 29-36.

[42] H.G.M. Edwards, S.E.J. Villar, J. Jehlicka, T. Munshi, FT-Raman spectroscopic study of calcium-rich and magnesium-rich carbonate minerals, Spectrochim Acta A Mol Biomol Spectrosc, 61 (2005) 2273-2280.

[43] A. Aminzadeh, Fluorescence bands in the FT-Raman spectra of some calcium minerals, Spectrochimica Acta Part A: Molecular and Biomolecular Spectroscopy, 53 (1997) 693-697. [44] J.R. Bezouska, J. Wang, O.C. Mullins, Origin of limestone fluorescence, Applied Spectroscopy, 52 (1998) 1606-1613. 
[45] J. Wang, O.C. Mullins, Fluorescence of limestones and limestone components, Applied Spectroscopy, 51 (1997) 1890-1895.

[46] M. Gaft, R. Reisfeld, G. Panczer, Modern luminescence spectroscopy of minerals and materials, Springer, 2015.

[47] N. Senesi, T.M. Miano, M.R. Provenzano, G. Brunetti, Characterization, Differentiation, and Classification of Humic Substances by Fluorescence Spectroscopy, Soil Science, 152 (1991) 259-271.

[48] L. Burgio, R.J.H. Clark, Library of FT-Raman spectra of pigments, minerals, pigment media and varnishes, and supplement to existing library of Raman spectra of pigments with visible excitation, Spectrochimica Acta Part A: Molecular and Biomolecular Spectroscopy, 57 (2001) 1491-1521.

[49] M. Castillejo, M. Martín, M. Oujja, D. Silva, R. Torres, A. Manousaki, V. Zafiropulos, O.F. van den Brink, R.M.A. Heeren, R. Teule, A. Silva, H. Gouveia, Analytical Study of the Chemical and Physical Changes Induced by KrF Laser Cleaning of Tempera Paints, Analytical Chemistry, 74 (2002) 4662-4671.

[50] M. Oujja, M. Sanz, E. Rebollar, J.F. Marco, C. Domingo, P. Pouli, S. Kogou, C. Fotakis, M. Castillejo, Wavelength and pulse duration effects on laser induced changes on raw pigments used in paintings, Spectrochimica Acta Part A: Molecular and Biomolecular Spectroscopy, 102 (2013) 7-14.

[51] A. Nevin, A. Cesaratto, S. Bellei, C. Andrea, L. Toniolo, G. Valentini, D. Comelli, TimeResolved Photoluminescence Spectroscopy and Imaging: New Approaches to the Analysis of Cultural Heritage and Its Degradation, Sensors, 14 (2014) 6338. 